\title{
Design of Innovative Pedagogical Systems on Interdisciplinary Basis
}

\author{
Viktoriia V. Dokuchaieva ${ }^{1}$, Liudmyla M. Sbitnieva ${ }^{2}$, Nazip V. Khamitov ${ }^{3}$, Dmytro O. Chystiak ${ }^{4} \&$ Nataliia M. \\ Malaniuk $^{5}$ \\ ${ }^{1}$ Department of Preschool and Elementary Education, Educational and Research Institute of Pedagogy and \\ Psychology, Luhansk Taras Shevchenko National University, Starobilsk, Ukraine \\ ${ }^{2}$ Department of Musical Art and Choreography, Educational Scientific Institute of Culture and Arts, Luhansk Taras \\ Shevchenko National University, Starobilsk, Ukraine \\ ${ }^{3}$ Department of Philosophical Anthropology, G. S. Skovoroda Institute of Philosophy NAS of Ukraine, Kyiv, \\ Ukraine \\ ${ }^{4}$ Department of Romance Philology, Institute of Philology, Taras Shevchenko National University of Kyiv, Kyiv, \\ Ukraine \\ ${ }^{5}$ Kyiv College of Transport Infrastructure, Kyiv, Ukraine \\ Correspondence: Liudmyla M. Sbitnieva, Luhansk Taras Shevchenko National University, 1 Gogol Square, \\ Starobilsk, 92703, Ukraine.
}

Received: June 10, 2020

Accepted: August 3, 2020

Online Published: August 7, 2020

doi:10.5430/ijhe.v9n7p267

URL: https://doi.org/10.5430/ijhe.v9n7p267

\begin{abstract}
The urgency of the problem raised in the article is determined by: evolutionary trends in education related to the need to design prospects for its development on an innovative basis; undeveloped conceptual foundations of designing innovative pedagogical systems on an interdisciplinary basis, reflecting the dialectical unity of theoretical and technological aspects of the design process; increasing the requirements for the quality of design activities in the process of preparation for practical implementation and improvement of innovations; insufficient development of the technological and methodological apparatus for measuring and evaluating the effectiveness of the process of designing innovative pedagogical systems on an interdisciplinary basis; the need to create an infrastructure for pedagogical design and accumulation of a database of pedagogical projects. The research was conducted as a project study (DBR) for three years (2017-2020) using mixed methods: unstructured interviews, the method of expert evaluations (based on the method of pairwise comparison), qualimetric methods of assessing the quality of pedagogical projects, statistical methods of data processing and testing hypotheses. The study showed that the effectiveness of the design of innovative pedagogical systems on an interdisciplinary basis is ensured by the creation of an external information and educational environment for the design of innovative systems and monitoring of design activities. In terms of content, they reflect the main provisions of the study and provide its experimental verification. The study developed an instrument for expert evaluation of projects of innovative pedagogical systems on an interdisciplinary basis, covering the project presentation scheme, summative and prognostic criteria of examination in socio-pedagogical, psychological and pedagogical, scientific and methodical, managerial and technical areas, methods of project quality assessment. The conclusions and recommendations of the study can be the basis for improving the educational process in educational institutions, as well as the development of pedagogical design practices.
\end{abstract}

Keywords: pedagogical design, innovative pedagogical systems, interdisciplinary principles, pedagogical invention, modelling and experiment

\section{Introduction}

The current historical stage, characterized by the globalization of problems that require the participation of the entire world community, leads to a change in the paradigm of education, which poses fundamentally new challenges to the educational sphere. Accelerating the pace of socio-economic development requires each person to focus on tomorrow, the ability to plan and evaluate life and professional prospects (Sax, 2018). These tendencies urge the problem of designing innovative pedagogical systems, give it an interdisciplinary nature, make it large-scale and modern. 
Experiencing a stage of thorough methodological transformation and rethinking, design penetrates deeper into all humanities fields of scientific knowledge as a technology of modern culture and as a basis for creating innovative systems with which teachers associate solutions to improve the quality of education (Johansson-Sköldberg, Woodilla \& Çetinkaya, 2013). Pedagogical design, following a systemic structure, is a subsystem of a more general system of professional education (Agostinho, Bennett, Lockyer \& Harper, 2011). Therefore, the general patterns apply to the creation, operation and development of the studied innovation system (Wrigley \& Straker, 2015). Designing innovative pedagogical systems on an interdisciplinary basis is a special area of activity that involves solving research problems of increased complexity related to the identification of the whole set of pedagogical factors and conditions that contribute to or hinder the implementation of scientific recommendations in the real educational process.

Designing innovative pedagogical systems on an interdisciplinary basis is a creative-innovative-expert activity (Gasson \& Waters, 2013; Hero \& Lindfors, 2019). Its essence is to develop pedagogical innovations on an interdisciplinary and transdisciplinary basis as tools for the development of pedagogical systems using humanitarian expertise and experimental testing (Aarikka-Stenroos, Sandberg \& Lehtimäki, 2014; Dell'Era, Marchesi \& Verganti, 2010). Design of innovative pedagogical systems is considered as a system of standards, technology of quality management of pedagogical systems taking into account the dynamics of cultural and educational context, as a "cultural form of innovation in education" (Bruton, 2011; Carlgren, Rauth \& Elmquist, 2016), technology of creating author's pedagogical systems (Dunne \& Martin, 2016). The design of innovative pedagogical systems is both a technology for the development of the pedagogical system and a technology for professional and personal self-development of a teacher. Pedagogical design provides impetus and has significant potential for the development of the subjective potential of the designing teacher (Braun \& Clarke, 2016; Law, Niederhauser, Christensen \& Shear, 2016; Montani, Odoardi \& Battistelli, 2014).

The main task of designing innovative pedagogical systems on an interdisciplinary basis is to design: heterogeneous (multicultural, polystylistic, inclusive, open) educational environment (Hye-Jin, 2017; Reuveni \& Vashdi, 2015); educational models of the "right future", author's pedagogical concepts, author's pedagogical system (Ankrah \& Al-Tabbaa, 2015; Hero, 2017); pedagogical processes at the conceptual and technological level and in different contexts (Tharp \& Tharp, 2013); pedagogical goals consistent with the author's conceptual ideas (Nabi, 2014); holistic content-procedural constructs - modules that correlate with conceptual ideas and strategic goals (Beckman \& Barry, 2017; Engeström \& Sannino, 2010); effective forms of pedagogical interaction, author's techniques, teaching technologies with their further implementation (Biffi, Bissola \& Imperatori, 2017); flow charts of training sessions at the local technological level, educational situations, criterion scales, diagnostic methods (Klaassen, 2018; Voogt et al., 2015).

The education system is characterized by diverse connections with different social and scientific spheres. So, most of the issues related to its renewal appear as complex interdisciplinary problems. Theoretical and methodological concepts that emerge at the junction of pedagogical and other knowledge become the core of new integrative academic subjects, the basis for constructing scientific areas of knowledge of the education innovative development processes (Dunne \& Martin, 2016). Therefore, pedagogical design is a special field of activity, covering the solution of research problems of increased complexity associated with the identification of the whole set of pedagogical factors and conditions that contribute to or hinder the implementation of scientific recommendations in the real educational process.

\section{Materials and Methods}

The study was conducted as a design-based research (DBR) using two iterations over three years (2017-2020). The project sought to explore what elements, methods, processes and practices could contribute to the creation of reflective, innovative and motivating learning structures for teachers in the educational environment.

As a component of design activity, the pedagogical experiment was characterized by a specific goal, object, subject, methods, stages of implementation and result.

The goal of the pedagogical experiment as a component of design was to obtain reliable data on the effectiveness of the model of the innovation system. Its implementation reduces the risk of introducing low-quality projects into the educational process. The object of the designer's experimental activity was the efficiency of the constructed innovation system. The subjects of the pedagogical experiment were teachers-designers who were directly involved in the organization and conduct of the experiment.

The methods of pedagogical experiment include quantitative data processing and qualitative analysis of its results. 
The pedagogical experiment was linear with the possibility of carrying out the necessary correction procedures by repeating some stages of the experiment.

The study used mixed methods: unstructured interviews were conducted with all respondents who created projects of innovative pedagogical systems (students and teachers), the method of expert evaluations, monitoring of design activities (based on the method of pairwise comparison), qualimetric methods of assessing the quality of pedagogical projects, statistical methods of data processing and testing of hypotheses.

\subsection{Research Design}

Based on classical ideas about design, stages of traditional design activities, as well as given the concept of designing innovative pedagogical systems on an interdisciplinary basis, the following stages of design are identified: creation of a pedagogical invention, creation of a single prototype, organization and implementation of a pedagogical experiment (Figure 1).

These stages of designing innovative pedagogical systems on an interdisciplinary basis reflect its procedural aspect. Creation of a pedagogical invention, modelling and experiment are its main components of a system. At the same time, the connection between the procedural and component aspects is realized in the following way. At the first stage, the designer works on a pedagogical invention, at the third - carries out a pedagogical experiment, at the second and fourth — implements modelling.

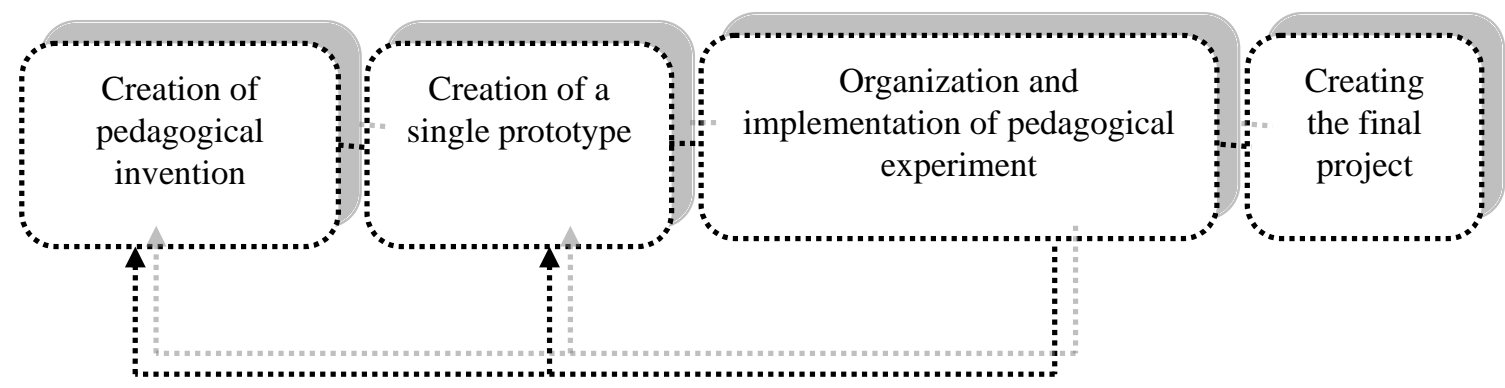

Figure 1. Stages of designing innovative pedagogical systems on an interdisciplinary basis

The stage of creating a pedagogical invention - its expected result is an inventive idea that requires further transformation into a particular system. In general, this stage involves awareness of the existing problem and finding some way to solve it. The general scheme of consistent realization of information functions at the stage of creating a pedagogical invention is presented in Figure 2.

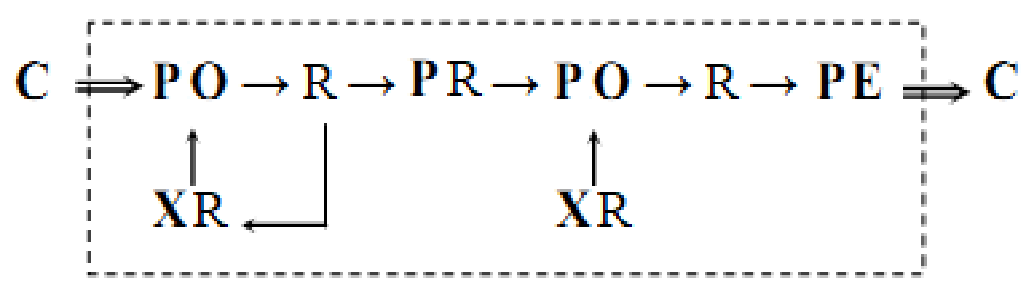

Figure 2. The sequence of realization of information functions at the stage of creating a pedagogical invention

Abbreviated designations of information functions will be hereinafter used: $\mathrm{PO}-$ reception; XR- storage; Rrecognition; PR- transformation; PE- information transfer.

Pedagogical invention as a component of designing innovative pedagogical systems on an interdisciplinary basis determines and directs the process of creating a project, ensures its novelty, specifics and a more rational way to solve the current pedagogical problem. It is characterized by the following provisions: the objective is a new solution to the problem, which will be the basis for building an innovation system; the object is a new relationship that reflects the features of the current situation and ways to take them into account to achieve the set objectives; the subject is a designing teacher; methods - methods of creative activity; the stages are understanding of the problem, its solution and verification of the solution; the result is an actual pedagogical invention that meets the capabilities of the teacher, is theoretically substantiated, reflected in detail and evaluated.

The stage of creating a single prototype. The inventive idea obtained at the first stage must accumulate all the 
qualities of the system being built and be realized in a technology, method, etc. Focusing on a particular pedagogical structure, personal experience and modern ideas, it is necessary to create a new model of a structure, which is based on an inventive idea. The general scheme of consistent realization of information functions at the stage of creating a single prototype is presented in Figure 3.

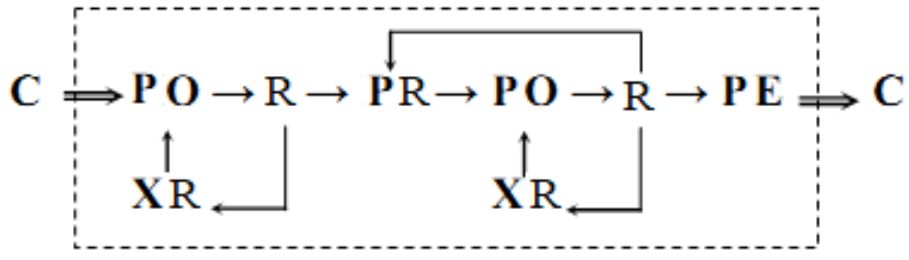

Figure 3. The sequence of realization of information functions at the stage of creating a single prototype

This stage is implemented by the method of modelling. As a component of designing innovative pedagogical systems on an interdisciplinary basis, modelling is characterized by the following provisions: the objective is to obtain a model of the designed innovative pedagogical system, which has all its features, novelty, can ensure solving the problem, is ready for mass use and has full information and documentary support; the object is an innovative pedagogical system, the construction and implementation of which in the educational process contributes to the solution of an urgent pedagogical problem; the subject is a designing teacher; methods- creative and eliminative modelling; stages- problem statement, model creation, its research, knowledge transfer; the result is a new model of the pedagogical system.

Stage of organization and implementation of pedagogical experiment. The experiment in the process of designing innovative pedagogical systems has a special place, because its results determine the direction of further activities: either the preparation of the project for mass use or its adjustment. The general scheme of consistent realization of information functions is presented in Figure 4.

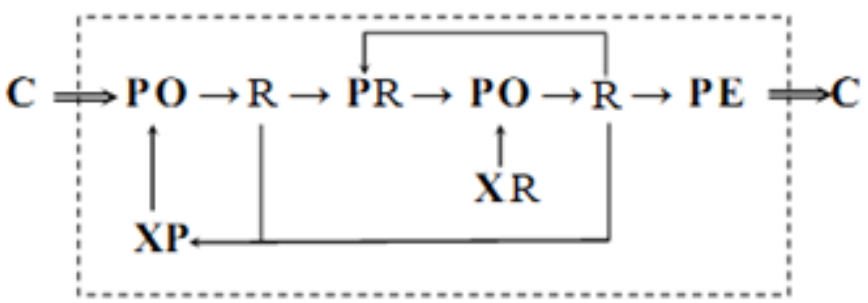

Figure 4. The sequence of realization of information functions at the stage of pedagogical experiment

As a component of designing innovative pedagogical systems on an interdisciplinary basis, the pedagogical experiment is characterized by the following provisions: the objective is to obtain reliable data on the effectiveness of the model of innovative pedagogical system; the object is the effectiveness of the created innovative pedagogical system on an interdisciplinary basis; the subjects are a designing teacher who participates in the organization and conduct of the experiment, and teachers who experimentally evaluate projects through their implementation in educational practice; the methods are methods of quantitative data processing and qualitative analysis of the result; the stages are the formalization of the problem, experiment planning, data analysis; the result is a conclusion on the effectiveness of the created innovation system.

The stage of creating the final project. At this stage, constructive changes are made in the created model in order to prevent its insignificant features and add those aspects that are important for the future implementation of the model. These constructive changes provide the created project with an opportunity of being used in mass pedagogical practice. The general scheme of sequence of realization of information functions at a stage of creation of the final pedagogical project is presented in Figure 5.

This stage is realized by means of eliminative modelling. The model that is built at this stage is eliminative only for a single prototype. The considered stage is the most responsible in terms of preparation of information support of the pedagogical project as the information on its essence, maintenance and conditions of use should be unambiguously interpreted by any teacher. As a rule, the created single prototype, provided its high efficiency, remains in use of its creator, and the final project passes to mass pedagogical experience. 


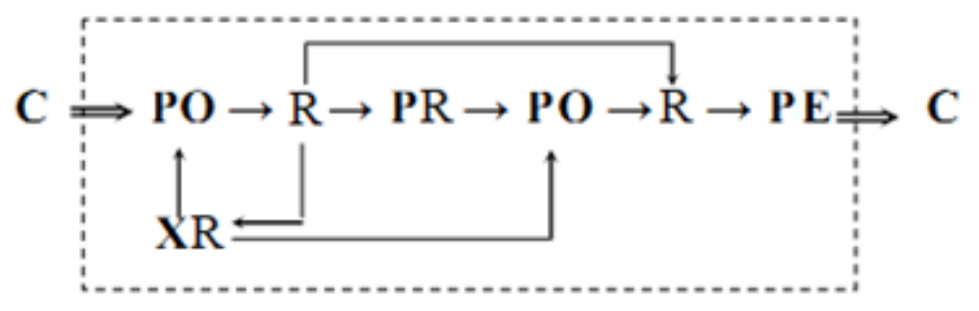

Figure 5. The sequence of realization of information functions at the stage of creating the final pedagogical project

\section{Results}

The study of design on an interdisciplinary basis as an innovative pedagogical system, activities and information transformation was based on the following provisions: the creation of an external information and pedagogical environment for the design of innovative pedagogical systems and monitoring of design activities.

The general provisions of the organization of a pedagogical experiment to verify their impact on the effectiveness of design activities were: construction of a pedagogical experiment in the traditional way with the involvement of the control (CG) and experimental (EG) groups. Some influence was purposefully exercised in the experimental group, while no influence was exercised in the control group.

As part of the experimental work to assess the impact of external information and pedagogical environment on the effectiveness of design activities, i.e. on the quality of the design activity, an external information and pedagogical environment was purposefully created for each project, covering: regulations of different levels(laws, statutes, orders, decisions of pedagogical and educational-methodical boards, self-government bodies); conclusions of various specialists who conducted research within the problem (lawyers, psychologists, physicians, social educators); literature on the problem and reference material needed for work on the project. At the same time, the participants of the experiment used the provided information, forming their own information and pedagogical environment in which the project was conducted. As a result, they created an information file, which reflected productive innovative ideas, the results of generalization of effective experience, fragments of the content of innovation systems, literature on topics, the most important quotes from legal and scientific-pedagogical sources, information on project performance. The information bank formed in this way was replenished and updated in the creation of the next pedagogical project. Experience has shown that the use of a data bank within the design activities greatly optimizes the work of a particular teacher, allows it to be organized on a scientific basis.

Two groups were formed to conduct the experiment. Experimental basis was the projects created by students of the Faculty of Socio-Economic Education and Management and the Faculty of Physics and Mathematics of the National Pedagogical Dragomanov University (7 projects) and current teachers of higher educational institutions in terms of information support (8 projects). Students carried out design activities during their pedagogical externship and in the study of the special course "Pedagogical Technologies". Teachers created projects within the research work of the educational institution to improve innovation activity. The control group included projects received without the creation of an external information and pedagogical environment by students of the Faculty of Physics and Mathematics of the National Pedagogical Dragomanov University during pedagogical externship and preparation of qualification papers (7 projects), as well as current teachers of higher educational institutions. The quality of each project was evaluated by an expert group consisting of the rector and vice-rectors and four teachers of the higher educational institution (two PhDs and two Drs).

Expert evaluation of the pedagogical project was carried out taking into account the socio-pedagogical, psychological-pedagogical, valeological, scientific-methodical, managerial, financial-economic and material-technical aspect on the three-point scale: the quality is expressed quite accurately -2 points; quality is expressed insufficiently -1 point; quality is not expressed -0 points. Summarizing these points, we get a project evaluation in the range from 0 to 80 points. The high quality of the project was evidenced by the scores of 63 to 80 points, the average -41 to 62 points, low - no more than 40 points.

We tested the following hypothesis: projects implemented in EG do not exceed the quality of projects created in CG. To do this, we used the Mann-Whitney test (Sidorenko, 1996; Alvesson \& Sandberg, 2011), which allows us to assess the significance of differences (shift) in the distributions of the data by samples. The use of this criterion in the experimental conditions involved the following procedures: 
1) Quality assessment of all CG and EG projects (each project is assigned a quality level);

2) The estimates received in two groups are combined in the general set and are ranked in descending order;

3) The value of Mann-Whitney statistics is calculated by the formula (1):

$$
U=n_{1} n_{2}+0,5 n_{x}\left(n_{x}+1\right)-T_{x}
$$

Where $n_{1}$ and $n_{2}$-the number of subjects in the first and second groups; $T_{x}$ - the greater of the two rank sums, $n_{x}$ - the number of subjects in the group with the largest sum of ranks;

4) Comparison of the obtained value with the tabular one at the selected level of significance: if the empirical value is greater, the hypothesis is accepted, otherwise it is rejected.

The data obtained and their processing using the Mann-Whitney test are shown in Table 1. Since the tabular value of the statistics $U$ exceeds the empirical one, the hypothesis of insignificance of differences is rejected and the alternative hypothesis is accepted at the level of significance of 0.05: the results obtained in EG are higher than in CG, i.e. the creation of an external information and pedagogical environment improves the quality of the created projects of innovative pedagogical systems on an interdisciplinary basis.

Table 1. Mann-Whitney test at the significance level of 0.05

\begin{tabular}{|c|c|c|c|c|c|}
\hline \multirow[b]{2}{*}{ Project No. } & \multicolumn{2}{|c|}{ Experimental group $\left(n_{1=15}\right)$} & \multicolumn{2}{|c|}{ Control group $\left(n_{2}=16\right)$} & \multirow{2}{*}{$\begin{array}{c}\text { Quality } \\
\text { level }\end{array}$} \\
\hline & $\begin{array}{l}\text { Number of } \\
\text { points }\end{array}$ & $\begin{array}{l}\text { Rank in the } \\
\text { total set }\end{array}$ & $\begin{array}{l}\text { Number } \\
\text { of points }\end{array}$ & $\begin{array}{c}\text { Rank in the } \\
\text { total set }\end{array}$ & \\
\hline 1. & 80 & 30.5 & & & III \\
\hline 2. & 80 & 30.5 & & & III \\
\hline 3. & 76 & 29 & & & III \\
\hline 4. & 75 & 28 & & & III \\
\hline 5. & & & 72 & 27 & III \\
\hline 6. & & & 63 & 26 & III \\
\hline 7. & 62 & 25 & & & II \\
\hline 8. & & & 61 & 24 & II \\
\hline 9. & 60 & 23 & & & II \\
\hline 10. & 57 & 22 & & & II \\
\hline 11. & & & 55 & 21 & II \\
\hline 12. & 53 & 20 & & & II \\
\hline 13. & & & 52 & 19 & II \\
\hline 14. & & & 51 & 17 & II \\
\hline 15. & 51 & 17 & & & II \\
\hline 16. & & & 51 & 17 & II \\
\hline 17. & 49 & 15 & & & II \\
\hline 18. & 47 & 14 & & & II \\
\hline 19. & & & 46 & 13 & II \\
\hline 20 & & & 45 & 12 & II \\
\hline 21. & & & 44 & 11 & II \\
\hline 22 & 40 & 10 & & & I \\
\hline 23. & 39 & 9 & & & I \\
\hline 24. & & & 37 & 8 & I \\
\hline
\end{tabular}




$\begin{array}{lccccc}25 . & 36 & & & & \text { I } \\ 26 . & & 36 & 6,5 & \text { I } \\ 27 . & 5 & & & & \text { I } \\ 28 . & & 32 & 4 & \text { I } \\ 29 . & & 30 & 3 & \text { I } \\ 30 . & & 29 & 2 & \text { I } \\ 31 . & & 28 & 1 & \text { I } \\ \text { anks (T) } & & & & 211.5 & \\ \text { value of U } & & 75.5 & & & \end{array}$

For greater clarity, we demonstrate the data obtained in Figure 6, combining the projects of each group according to quality levels.

As shown by the grouping in the experimental group, the number of projects implemented at a high level is more than twice as high as in the control group. At the same time, the number of low-level projects is lower by $10.8 \%$. Thus, the creation and development of external information and educational environment for designing innovative pedagogical systems on an interdisciplinary basis is an essential condition that increases the effectiveness of its implementation, as it affects not only the procedural aspect, but also to some extent determines the content, type and effectiveness of the project.

Creating a pedagogical project is a long process and requires constant monitoring at every stage. Therefore, in addition to the internal evaluation of design activities carried out within the pedagogical experiment, external consistent monitoring of the design results was used, the possibility of which provides pedagogical monitoring. We distinguish organizational and procedural aspects in the structure of pedagogical monitoring. The first reflects the hierarchical links of the implementation of procedures for collecting, storing and processing the necessary pedagogical information, which, depending on the task, may involve certain management levels of the pedagogical system: a particular subject teacher, methodological association, rector (director) of the educational institution or his deputies, sponsors, etc. The procedural aspect in the structure of pedagogical monitoring determines the content and sequence of its stages, each having a purpose, goals and methods of implementation (survey, questionnaire, rating, testing, observation, pedagogical consultation, mathematical methods, heuristic methods).

Pedagogical design of innovative systems is a process. The elementary unit of this process is the formulation and solution of operational pedagogical task. Its change determines the stage structure of this process, which involves the creation of a pedagogical invention, the creation of a single prototype, the organization and implementation of a pedagogical experiment, the creation of the final project. Their ideas are most productive on the basis of information functions that make up the information model. The stages differ in the content of input information and the sequence of information functions (See Figure 6).

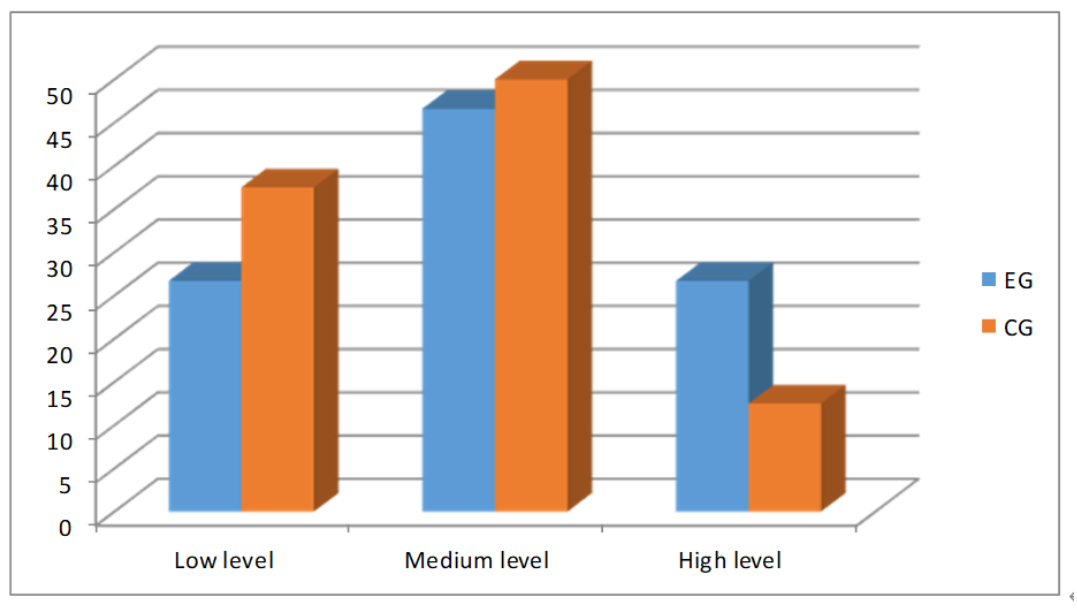

Figure 6. Distribution of projects of the control and experimental groups by quality levels 
Monitoring the design activities of innovative pedagogical systems on an interdisciplinary basis provided a generalized assessment of projects created within the experimental study by external independent experts who did not participate in the monitoring procedures. The method of pairwise comparison was selected as the most effective method of project evaluation, which provided a sufficient volume of data to obtain objective conclusions. For this purpose, a number of projects created at random and after appropriate training were selected. The expert compared each project built in EG in pairs with all CG projects on the basis of recorded indicators. Table 2 shows a fragment of the form to be filled out by an expert.

Table 2. Project examination form

\section{Dear expert!}

Please compare pedagogical projects $\boldsymbol{\Pi}$ and $\boldsymbol{n}$ using the following scale:

"-"-this indicator is worse in project $\boldsymbol{\Pi}$;

" 0 "-this indicator is the same;

“+”-this indicator is better in project $\boldsymbol{\Pi}$.

1. Urgency of the pedagogical problem solved within the project

2. Significance (demand for) of pedagogical innovations provided for by the project

3. The degree of massiveness of the project

4. Compliance with the regulatory framework of modern education

Summarizing the scores for each indicator, we obtain a value (positive, negative or zero), which was then compared with another project and characterizes the advantage of one project over another. For definiteness on the basis of $\Pi i$ and ni, projects with EG and CG were indicated respectively.

Experimental work to verify the impact of monitoring of pedagogical activities on the quality of the innovative project of the pedagogical system was carried out in the conditions of higher educational institutions. Practitioners were asked to create projects in accordance with the topic of research pedagogical work. To do this, working groups were created that collected the necessary information, identified urgent pedagogical problem, justified the choice of topic and the need to design a particular pedagogical object, carried out work on its design, testing and implementation in practice. Monitoring activities were conducted under the guidance of the rector, vice-rectors and leading methodologists. All projects created with the involvement of pedagogical monitoring had almost the same conditions: resource provision, time frame, volume and timeliness of assistance, sources of information. In addition to the projects created in these conditions, the experiment evaluated projects created without the involvement of pedagogical monitoring, which have already been used in the work of teachers, have a package of information and documentary support and are characterized by a certain level of efficiency.

A total of 10 projects were considered at this stage of the experiment. The experimental group was represented by 5 projects created by teams of teachers with the involvement of monitoring (projects No. 6, 7, 8, 9, 10), the control group - 5 projects created without monitoring (projects No. 1, 2, 3, 4, 5). In particular, the experimental group consisted of projects of innovation management system, organization of scientific and methodological work, quality control system of education, pedagogical technology, academic subject. The control group included projects of systems for improving the methodological activities of teachers and educational work, the model of a specialist, the academic subject, the organization of cycle commissions.

The experts invited to evaluate the projects used the method of pairwise comparison. They compared all projects with each other (a total of 45 comparisons) without information about the conditions under which these projects were created. The commission consisted of three experts, which provided an opportunity for everyone to get acquainted with all the projects. Table 3 shows the data of expert evaluation. A positive number in the i-th step and the j-th column indicate that the project with the number $\mathrm{j}$ is better than the project with the number $\mathrm{i}$. 
Table 3. The results of pairwise comparison of projects of innovative pedagogical systems on an interdisciplinary basis

\begin{tabular}{ccccccccccc}
\hline Project No. & 1 & 2 & 3 & 4 & 5 & 6 & 7 & 8 & 9 & 10 \\
\hline 1 & & 1 & 0 & 0 & 1 & 1 & 1 & 1 & 1 & 1 \\
2 & -1 & & -1 & -1 & -1 & 0 & 0 & 1 & -1 & 0 \\
3 & 0 & 1 & & 0 & 0 & 1 & 1 & 1 & 1 & 1 \\
4 & 0 & 1 & 0 & & 0 & 1 & 0 & 1 & -1 & 1 \\
5 & -1 & 1 & 0 & 0 & & 1 & 0 & 1 & 0 & 1 \\
6 & -1 & 0 & -1 & -1 & -1 & & -1 & 1 & -1 & 0 \\
7 & -1 & 0 & -1 & 0 & 0 & 1 & & 1 & 0 & 1 \\
8 & -1 & -1 & -1 & -1 & -1 & -1 & -1 & & -1 & 0 \\
9 & -1 & 1 & -1 & 1 & 0 & 1 & 0 & 1 & & 1 \\
10 & -1 & 0 & -1 & -1 & -1 & 0 & -1 & 0 & -1 & \\
Total & -7 & 4 & -6 & -3 & -3 & 5 & -1 & 8 & 3 & 6 \\
points & & & & & & & & & & \\
Rank & 10 & 4 & 9 & 7 & 7 & 3 & 5 & 1 & 7 & 2
\end{tabular}

The ranking of the comparison results showed that four projects (except No. 9) created against the background of monitoring of design activities were at the top of the ranking list. Three projects created arbitrarily (No. 1, 3 and 5) were the worst in the sample. In general, the ranking of projects was as follows: $8,10,6,2,\{7,9,4\}, 5,3,1$.

Let us consider the results of a pairwise comparison of projects created with the use of pedagogical monitoring and projects created arbitrarily (Table 4).

Table 4. The results of a pairwise comparison

\begin{tabular}{ccccccc}
\hline Project No. & 6 & 7 & 8 & 9 & 10 & Total points \\
\hline 1 & 1 & 1 & 1 & 1 & 1 & 5 \\
2 & 0 & 0 & 1 & -1 & 0 & 0 \\
3 & 1 & 1 & 1 & 1 & 1 & 5 \\
4 & 1 & 0 & 1 & -1 & 1 & 2 \\
5 & 1 & 0 & 1 & 0 & 1 & 3 \\
Total points & 4 & 2 & 5 & 0 & 4 & 15
\end{tabular}

The results of pairwise comparison of the two groups of projects showed that project No. 8 is better than five projects created arbitrarily, projects No. 10 and 6 - four, project No. 7 - two. The data in the last column should be interpreted with the opposite sign: projects No. 1 and 3 are worse than all five projects created with the involvement of pedagogical monitoring, project No. 5 is worse than three of them, project No. 4 is worse than two.

Using the criterion of signs, we test the hypothesis of the superiority of the projects of the experimental group over the projects of the control group. The total number of significant assessments is 19 , of which 17 are positive and 2 are negative. Thus, the "typical" estimate is positive. The empirical value for the sign criterion is the number of "atypical" estimates, i.e.- 2 . At the significance level of 0.01 , number 4 is critical for a set of 19 elements (Bucolo, Wrigley \& Matthews, 2012). The obtained experimental data confirm the hypothesis.

Thus, the support of designing innovative pedagogical systems on an interdisciplinary basis by specially organized monitoring provides timely assistance in the process of working on the project, evaluation of its results, correction of shortcomings, which increases the efficiency of design activities.

\section{Discussions}

The study of the essential features of innovative pedagogical systems was based on general systems theory (Burke, 2013), organizational theory (Voogt et al., 2015), the concept of research of behavioural (purposeful) systems (Hye-Jin, 2017), the concept of self-organization (Johansson-Sköldberg, Woodilla \& Çetinkaya, 2013; Klaassen, 
2018). This provided the basis for defining an innovative pedagogical system as a complex phenomenon that belongs to the class of social systems and contains systemic (organizational) features (properties) - in internal relations, and synergetic (self-organizational) - in external relations (interactions).

Design of innovative pedagogical systems on an interdisciplinary basis is based on pedagogical invention, modelling and experiment, which is implemented on the basis of stages of pedagogical design (creation of pedagogical invention, creation of a single prototype, organization and implementation of pedagogical experiment, creation of final project) and information conversion functions(receiving, recognizing, transmitting, converting and storing).

The effectiveness of designing innovative pedagogical systems on an interdisciplinary basis from the standpoint of the system, activities and information transformation was ensured on the basis of creating an external information and pedagogical environment for designing innovative systems and monitoring design activities. This allowed the participants to ensure, on an interdisciplinary and transdisciplinary basis, the formation or development of professional competence based on the experience of pedagogical reflection, pedagogical design, design at the conceptual, content-procedural and local-technological levels of author's pedagogical systems, motivation and professional-personality self-development.

The findings of the study were consistent with the conclusions of Burke (2013) that in modern context of modernization of the educational system one of the most pressing was the problem of building a holistic theory of pedagogical design, which ensures the effectiveness of design activities in creating and implementing innovative systems in educational practice. The results confirmed a previous study conducted by Weitze (2017), which draws attention to the need to develop an organizational and content scheme for designing innovative pedagogical systems on an interdisciplinary basis. The study also complements the theory and methodology of pedagogical design: first, complements the theoretical basis of pedagogical design as an interdisciplinary category of professional education (Dorst \& Cross, 2011), the generality of the category of forecasting and design in educational systems (Gulikers, Runhaar \& Mulder, 2017); provisions for the integration and differentiation of pedagogical design systems based on the synthesis of pedagogical and prognostic patterns (Cooper, Junginger \& Lockwood, 2009). Second, the results of this study help to better understand the importance of implementation of learning technologies, academic subjects and quality management systems in education in the design.

\section{Conclusions}

In the modern era, education has become one of the most important areas of human activity. Refusal of total regulation, the possibility of maximizing the creative potential of teachers is manifested in the preparation and implementation in the educational process of a variety of innovations that provide a higher level of quality of education. Every innovative system created in the conditions of modern education must be carefully prepared, reasoned, and tested, i.e. it must be designed.

One of the most important conditions for the development of innovative activities in education is the design of innovative pedagogical systems on an interdisciplinary basis, which are the basis for actualization and realization of the goals of methodological work and for determining the nature of its functioning and development. Designing innovative pedagogical systems on an interdisciplinary basis covers three main components, each having its own functional purpose and contributes to the common goal: pedagogical invention provides novelty of the project, modelling - creating a pedagogical structure of the required type, experiment - testing its effectiveness. The implementation of the components of design activities is carried out on the basis of the stages of creation of a pedagogical invention, the creation of a single prototype, the organization and implementation of a pedagogical experiment and the creation of the final project. At the first stage the inventive idea which provides novelty of the project is formulated. At the second stage - the pedagogical object of the set type which efficiency is estimated at a stage of the organization and realization of pedagogical experiment is formed by means of creative modelling. The last stage ensures the preparation of the project for mass use: an elimination model of the pedagogical object is created, for which information support is documented. The result is the creation of an innovative system of a certain type, which has the features of a pedagogical project and is prepared for large-scale use.

We see the prospect of further research in: identifying new patterns and principles of pedagogical design, innovative factors and conditions for successful functioning and development of design activities; development of methodological and technological support of the process of pedagogical design; development of effective qualimetric tools of design activity. Further studies can also cover design of polysystem pedagogical objects; personalized innovative pedagogical systems; socio-pedagogical systems in a wide educational space, as well as targeted training of competent actors in the process of designing innovative pedagogical systems; updating the value background of innovative and pedagogical design in the context of European integration processes in the modern educational megaspace. 


\section{Limitations and Implications for the Research}

The results of the study can be challenged, as the experiment was an experience for one higher educational institution and with a limited number of respondents. In addition, the study assessed the actual quality of the pedagogical project (the quality of its readiness for use and the effectiveness of its operation) on the basis of expert assessments, so such assessments had a share of subjectivity based on the human factor. The results of the study rely on only one group of sample respondents and experts. The quasi-experimental design of the study and a number of studied variables were also limitations of this study.

\section{References}

Aarikka-Stenroos, L., Sandberg, B., \& Lehtimäki, T. (2014). Networks for the commercialization of innovations: A review of how divergent network actors contribute. Industrial Marketing Management, 43(3), 365-381. https://doi.org/10.1016/j.indmarman.2013.12.005

Agostinho, S., Bennett, S., Lockyer, L., \& Harper, B. (2011). The future of learning design. Learning, Media and Technology, 36(2), 97-99. https://doi.org/10.1080/17439884.2011.553619

Alvesson, M., \& Sandberg, J. (2011). Generating research questions through problematization. Academy of Management Review, 36(2), 247-271. https://doi.org/10.5465/AMR.2011.59330882

Ankrah, S., \& Al-Tabbaa, O. (2015). Universities - industry collaboration: a systematic review. Scandinavian Journal of Management, 31(3), 387-408. https://doi.org/10.2139/ssrn.2596018

Beckman, S., \& Barry, M. (2017). Innovation as a learning process: Embedding design thinking. California Management Review, 50(1), 25-56. https://doi.org/10.2307/41166415

Biffi, A., Bissola, R., \& Imperatori, B. (2017). Chasing innovation: a pilot case study of a rhizomatic design thinking education program. Education + Training, 59(9), 957-977. https://doi.org/10.1108/ET-01-2016-0007

Braun, V., \& Clarke, V. (2016). Using thematic analysis in psychology. Qualitative Research in Psychology, 3, 77-101. https://doi.org/10.1191/1478088706qp063oa

Bruton, D. (2011). Learning creativity and design for innovation. International Journal of Technology and Design Education, 21(3), 321-333. https://doi.org/10.1007/s10798-010-9122-8

Bucolo, S., Wrigley, C., \& Matthews, J. (2012). Gaps in organizational leadership: Linking strategic and operational activities through design-led propositions. Design Management Journal, 7, 18-28. https://doi.org/10.1111/j.1948-7177.2012.00030.x

Burke, R. (2013). Project management: planning and control techniques. $5^{\text {th }}$ edition. Chichester, UK: Wiley.

Carlgren, L., Rauth, I., \& Elmquist, M. (2016). Framing design thinking: The concept in idea and enactment. Creativity and Innovation Management, 25(1), 38-57. https://doi.org/10.1111/caim.12153

Cooper, R., Junginger, S., \& Lockwood, T. (2009). Design thinking and design management: A research and practice perspective. Design Management Review, 20(2), 46-55. https://doi.org/10.1111/j.1948-7169.2009.00007.x

Dell'Era, C., Marchesi, A., \& Verganti, R. (2010). Mastering technologies in design-driven innovation. Research Technology Management, 53, 12-23. https://doi.org/10.1080/08956308.2010.11657617

Dorst, K., \& Cross, N. (2011). Creativity in the design process: co-evolution of problem-solution. Design Studies, 22(5), 425-437. https://doi.org/10.1016/S0142-694X(01)00009-6

Dunne, D., \& Martin, R. (2016). Design thinking and how it will change management education: An interview and discussion. Academy of Management Learning \& Education, 5(4), 512-523. https://doi.org/10.5465/AMLE.2006.23473212

Engeström, Y., \& Sannino, A. (2010). Studies of expansive learning: Foundations, findings and future challenges. Educational Research Review, 5(1), 1-24. https://doi.org/10.1016/j.edurev.2009.12.002

Gasson, S., \& Waters, J. (2013). Using a grounded theory approach to study online collaboration behaviors. European Journal of Information Systems, 22(1), 95-118.https://doi.org/10.1057/ejis.2011.24

Gulikers, J. T. M., Runhaar, P., \& Mulder, M. (2017). An assessment innovation as flywheel for changing teaching and learning. Journal of Vocational Education and Training, 70(2), 1-20. https://doi.org/10.1080/13636820.2017.1394353 
Hero, L.-M. (2017). Innovation tournament as a multidisciplinary activity system to promote the development of innovation competence. Journal of Professional and Vocational Education, 19(4), 8-31.

Hero, L.-M., \& Lindfors, E. (2019). Students' learning experience in a multidisciplinary innovation project. Education + Training, 61(4), 500-522. https://doi.org/10.1108/ET-06-2018-0138

Hye-Jin, N. (2017). An interdisciplinary design education framework. The Design Journal, 20(1), 835-847. https://doi.org/10.1080/14606925.2017.1353030

Johansson-Sköldberg, U., Woodilla, J., \& Çetinkaya, M. (2013). Design thinking: past, present and possible futures. Creativity and innovation management, 22(2), 121-146. https://doi.org/10.1111/caim.12023

Klaassen, R. (2018). Interdisciplinary education: a case study. European Journal of Engineering Education, 43(6), 842-859. https://doi.org/10.1080/03043797.2018.1442417

Law, N., Niederhauser, D. N., Christensen, R., \& Shear, L. (2016). A multilevel system of quality technology-enhanced learning and teaching indicators. Journal of Educational Technology and Society, 19(3), 72-83.

Montani, F., Odoardi, C., \& Battistelli, A. (2014). Individual and contextual determinants of innovative work behaviour: proactive goal generation matters. Journal of Occupational and Organisational Psychology, 87(4), 645-670. https://doi.org/10.1111/joop.12066

Nabi, A. Y. (2014). Technology of the designing of a quality assurance system of higher education on the basis of the EFQM model. International Journal of Education and Information Technologies, 8, 316-321.

Reuveni, Y., \& Vashdi, D. R. (2015). Innovation in multidisciplinary teams: the moderating role of transformational leadership in the relationship between professional heterogeneity and shared mental models. European Journal of Work and Organizational Psychology, 24(5), 678-692. https://doi.org/10.1080/1359432X.2014.1001377

Sax, D. (2018, December 7). End the innovation obsession: Some of our best ideas are in the rearview mirror. The New York r Times. from https://www.nytimes.com/2018/12/07/opinion/sunday/end-the-innovation-obsession.html

Sidorenko, E. V. (1996). Methods of mathematical processing in psychology. St.-Petersburg, Russia: Social'no-psihologicheskij centr.

Tharp, B., \& Tharp, S. (2013). Discursive design basics: Mode and audience. In E. Brandt, P. Ehn, T. D. Johansson, M. H. Reimer, T. Markussen, \& A. Vallgårda (Eds.), Proceedings of Nordic Design Research Conference: Experiments in Design Research, 406-409. Copenhagen, Denmark: KADK.

Voogt, J., Laferrière, T., Breuleux, A., Itow, R. C., Hickey, D. T., \& McKenney, S. (2015). Collaborative design as a form of professional development. Instructional Science, 43(2), 259-282. https://doi.org/10.1007/s11251-014-9340-7

Weitze, C. L. (2017). Designing pedagogical innovation for collaborating teacher teams. Journal of Education for Teaching, 43(3), 361-373. https://doi.org/10.1080/02607476.2017.1319511

Wrigley, C., \& Straker, K. (2015). Design thinking pedagogy: The educational design ladder. Innovations in Education and Teaching International, 11, 22-32. https://doi.org/10.1080/14703297.2015.1108214 